\title{
An Electronic Flash Lamp System to Replace the Traditional, Explosively - Driven Light Source
}

\author{
W. L. Stigman, R. Kihara, R. D. Scarpetti
}

This article was submitted to $25^{\text {th }}$ International Congress on High Speed Photography and Photonics, Beaune, France

September 29, 2002 - October 4, 2002

U.S. Department of Enaray

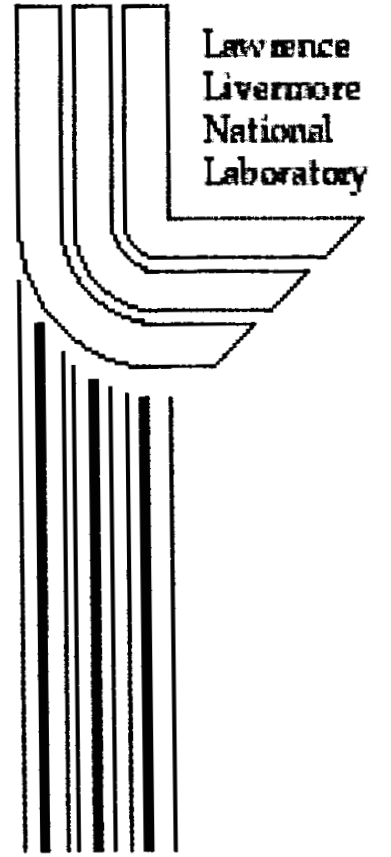

September 25, 2002 


\section{DISCLAIMER}

This document was prepared as an account of work sponsored by an agency of the United States Government. Neither the United States Government nor the University of California nor any of their employees, makes any warranty, express or implied, or assumes any legal liability or responsibility for the accuracy, completeness, or usefulness of any information, apparatus, product, or process disclosed, or represents that its use would not infringe privately owned rights. Reference herein to any specific commercial product, process, or service by trade name, trademark, manufacturer, or otherwise, does not necessarily constitute or imply its endorsement, recommendation, or favoring by the United States Government or the University of California. The views and opinions of authors expressed herein do not necessarily state or reflect those of the United States Government or the University of California, and shall not be used for advertising or product endorsement purposes.

This is a preprint of a paper intended for publication in a journal or proceedings. Since changes may be made before publication, this preprint is made available with the understanding that it will not be cited or reproduced without the permission of the author.

This report has been reproduced directly from the best available copy.

Available electronically at http://www.doc.gov/bridge

Available for a processing fee to U.S. Department of Energy

And its contractors in paper from

U.S. Department of Energy

Office of Scientific and Technical Information

P.O. Box 62

Oak Ridge, TN 37831-0062

Telephone: (865) 576-8401

Facsimile: (865) 576-5728

E-mail: reports@adonis.osti.gov

Available for the sale to the public from

U.S. Department of Commerce

National Technical Information Service

5285 Port Royal Road

Springfield, VA 22161

Telephone: (800) 553-6847

Facsimile: (703) 605-6900

E-mail: orders@ntis.fedworld.gov

Online ordering: http://www.ntis.gov/ordering.htm

OR

Lawrence Livermore National Laboratory

Technical Information Department's Digital Library

http://www.llnl.gov/tid/Library.html 


\title{
AN ELECTRONIC FLASH LAMP SYSTEM TO REPLACE THE TRADITIONAL, EXPLOSIVELY - DRIVEN LIGHT SOURCE
}

\author{
William L. Stigman, Ronald Kihara, Raymond D. Scarpetti*, \\ Lawrence Livermore National Laboratory \\ Livermore, CA USA
}

\begin{abstract}
Electronic flash lamps are being developed at the Lawrence Livermore National Laboratory (LLNL). These lamps are intended to replace the traditional explosively driven Argon-gas filled light sources (Argon candles) that are currently used to provide illumination for high speed rotating mirror-framing cameras. At Livermore, we are developing an electronic flash lamp system that can match or exceed the light output of a traditional Argon candle. These systems utilize a Plasma Arc Lamp ${ }^{1,2}$ developed by PRISM Science Inc of Chatham, MA, USA.
\end{abstract}

In the past, high-speed photography requiring explosively driven light sources were a one-time-only event that destroyed fixtures and optical alignment. The electronic flash lamp system, utilizing the Plasma Arc Lamp, will replace the explosively driven lighting systems and provide the capability to dry run experimental setups and repeat tests without damage to the experimental set-up. The electronic flash lamp system eliminates the problem of collateral damage to the experiment and does not add to the overall amount of explosives needed for a single test. Since the Pulsed-Power driver is remotely located, only the flash lamp itself is destroyed when the explosive shot is fired. The flexible geometry of this light source also enables the user to create complex light patterns as well as photograph very large areas with a single lighting system.

This electronic flash lamp system will provide an extremely bright, stable, and repeatable light source for rotating-mirror framing cameras operating at one million frames per second, using both black \& white or color films. The design of the Pulsed-Power driver and the flash lamp, along with experimental data and results will be discussed.

\section{KEYWORD LIST}

Flash Lamps, Light Sources, Rotating Mirror Cameras, Explosives, Illumination, High-Speed Photography.

\section{INTRODUCTION}

At LLNL we are in the process of transitioning from explosive lighting systems to electrically driven light sources. The reasons for this transition are that we have recently activated a Contained Firing Facility (CFF), which has a limited capacity to contain a detonation. The use of electrically driven light sources greatly reduces the explosive burden placed on the facility. Two years ago, we picked the Plasma Arc Lamp (PAL) for evaluation and characterization. The lamp has several advantages over other types of discharge lamps. Most importantly, the lamp has a light output that is on par with an explosive candle (1.6 Giga-Lumen), and secondly, the lamp is substantially less expensive than the alternatives. Adapting the lamp to our existing flashlamp system was not without its difficulties, as the electrical characteristics of the PAL differ significantly from the capillary lamps that we have been using to date. Unlike a capillary lamp, whose impedance stabilizes quickly when the plasma channel grows to fill the bore, the impedance of the PAL continues to change as a function of time, since the arc is free to expand. In the time frame of our tests, we were never able to achieve a steady-state condition. The PAL's impedance also varies with charge voltage, gas pressure, arc length, and ground-plane width, and it's intrinsic impedance is so low it is almost a short-circuit. We found it necessary to connect

\footnotetext{
* Raymond D. Scarpetti is currently at Los Alamos National Laboratory, Las Alamos New Mexico.
} 
lamps in series, and to adjust the lamp parameters to attain reasonable impedance. A matching low impedance power source also had to be constructed. We also found that initiating and maintaining the breakdown in a PAL required additional circuitry that is not required by a standard flashlamp.

In this paper we summarize the results of two years of research directed towards adapting the PAL lamp to our flashlamp banks. Much of our time was spent characterizing the dynamic impedance characteristics of the lamps as a function of several parameters, and characterizing and measuring the light output against our standard candle.

\section{MECHANICAL DESIGN}

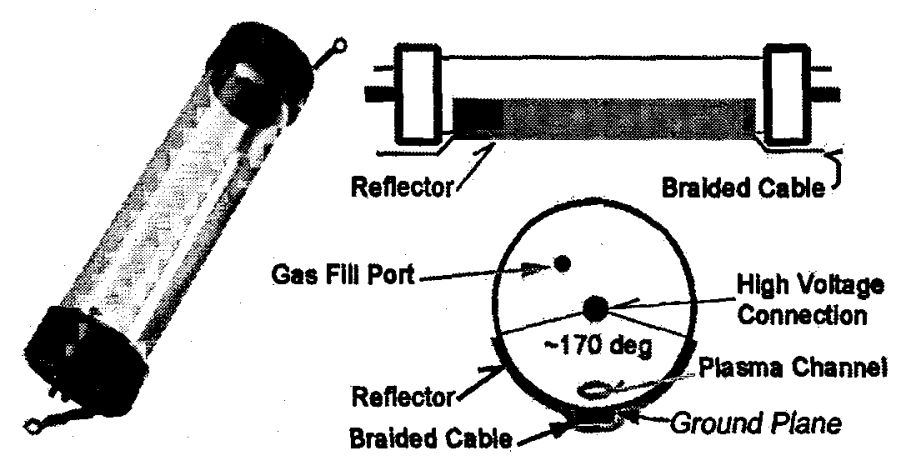

Fig. 1: Lamp Construction
The basic mechanical design for the PAL consists of a $7.6 \mathrm{~cm}$ diameter plastic tube, $30 \mathrm{~cm}$ long, with injection-molded end-caps. A ground-plane is attached to the outside of the tube. This ground-plane enables the formation of the plasma channel inside the tube. Braided cable runs on top of, and electrically attaches the ground-plane of each lamp to the next lamp. A reflector is attached to the outside of the tube to increase and focus light in the forward direction. The design of the reflector enables us to control the light pattern on the target. Gas fill ports and high-voltage connections are found on the end-caps at both ends of the lamps, enabling series lamp configurations.

\section{LAMP CHARACTERIZATION}

The electrical characteristics of the PAL differ so significantly from the capillary lamps that we have customarily used, that we found it necessary to construct a lamp test stand for testing and characterization. Current and voltage probes were attached to lamps within the test stand, as well as pressure sensors to monitor the gas pressure within the tube. The fill gas in all cases was Xenon. The lamp output of the lamps was measured with a vacuum photodiode aimed at a KODAK $18 \%$ gray card. Each shot was monitored on a digital oscilloscope and logged into a computer for digital postprocessing in IGOR. The current and voltage data were used to develop impedance curves as a function of time.

Once the test stand was operational, we started by comparing the behavior of a standard PAL configuration of three

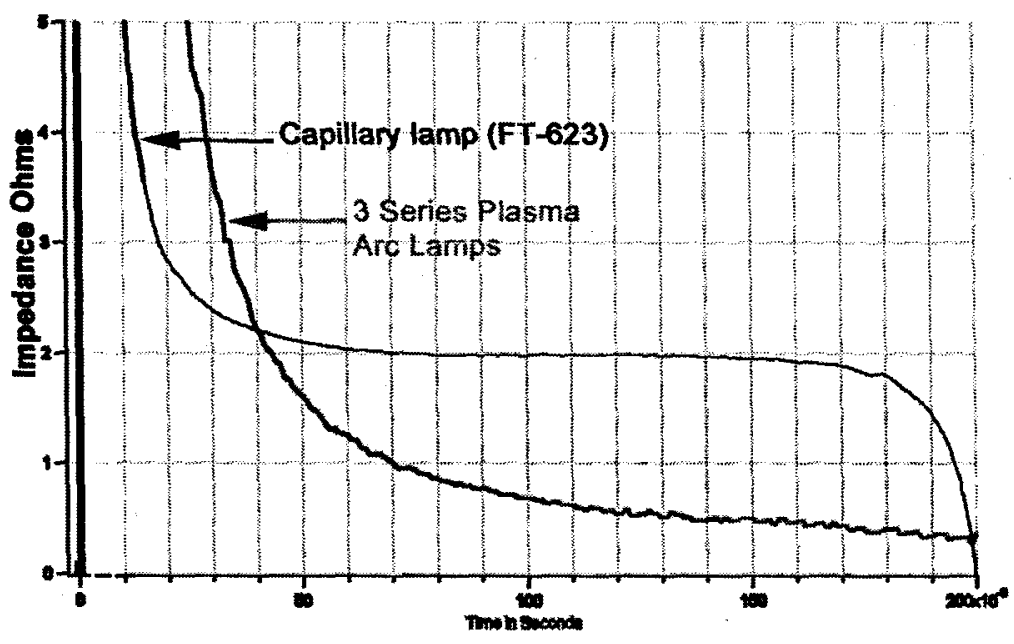

Figure 2, Impedance capillary vs. Plasma Arc Lamp lamps in series against a capillary lamp using our standard 2-ohm Pulse Forming Network (PFN). This is illustrated in Fig. 2. Note that the impedance curve of the capillary lamp, a FT-623, stabilizes rapidly after the establishment of the arc at 2-ohms, while the impedance of the PAL starts higher, crosses over, and then continues to fall over the duration of the discharge. We then adjusted one parameter at a time, holding the others fixed, and recording the effects. Our efforts were concentrated on parameter changes that would drive the lamp impedance up, as the low intrinsic impedance of the PAL made it difficult to design a PFN that could deliver the required current. 


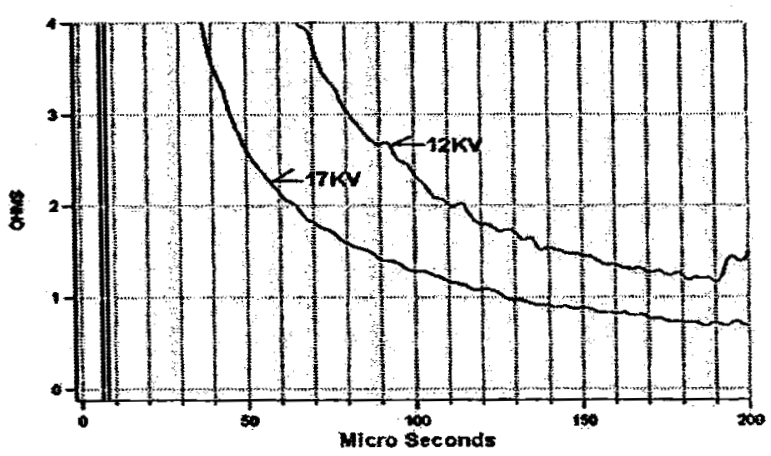

Fig. 3 Impedance vs. Voltage

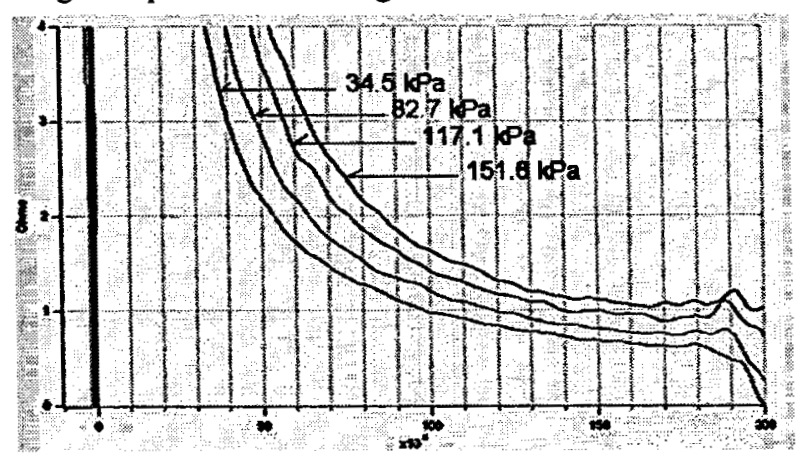

Fig. 4 Impedance vs. Pressure

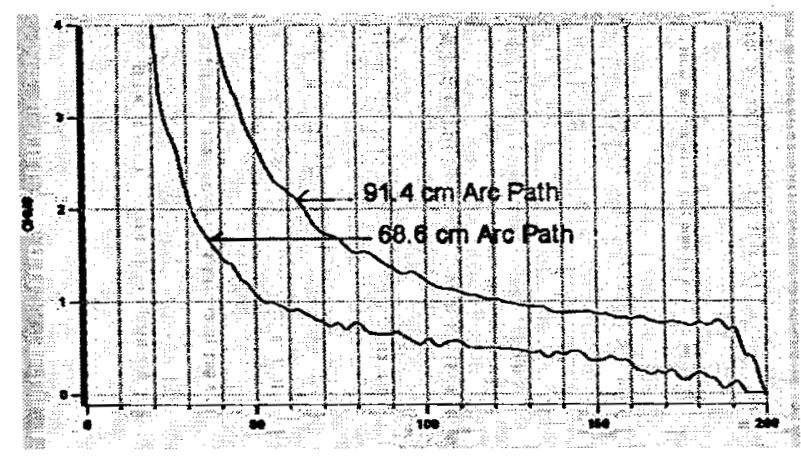

Fig. 5 Impedance vs. Arc Path

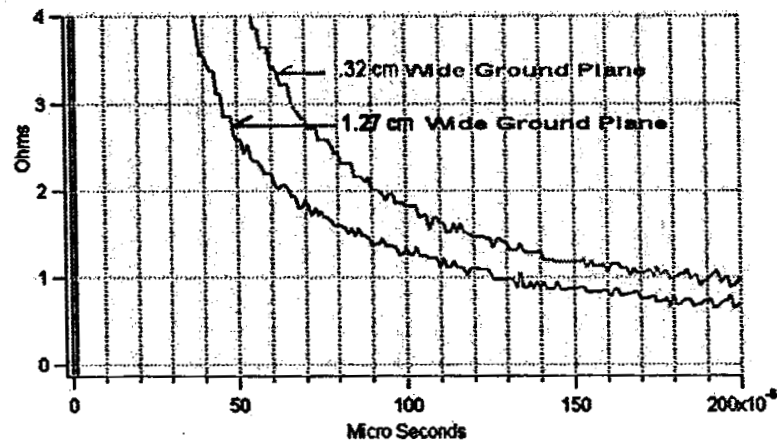

Fig. 6 Impedance vs. Ground Plane Width
The data used to generate the curves in Fig. 3, were used to determine the dynamic voltage-current relationship of the PAL. The data is regenerated here as a voltage-impedance plot, as an aid to developing our final PFN design. The gas pressure in this, and all of the tests where this was the fixed parameter, was 69 $\mathrm{kPa}$. All parameters measured after this, were taken at the standard $17 \mathrm{kV}$ operating voltage of the bank.

In Fig. 4, the impedance shift is plotted as a function of pressure. Pressures in the range of $117 \mathrm{kPa}$ to $152 \mathrm{kPa}$ gave us an impedance near one-ohm, which we later chose for our bank impedance. Large gains in light output were seen with increasing pressure up to $138 \mathrm{kPa}$, partially due to the better impedance match between the lamp and the PFN. Additional triggering circuitry had to be added at the higher pressures to trigger the lamps reliably.

The arc resistance increased with increasing arc length as expected. The impedances for two lamps $(68.6 \mathrm{~cm})$ and three lamps $(91.4 \mathrm{~cm})$ in series are plotted in fig. 5 .

Lastly, we changed the width of the ground plane from $1.27 \mathrm{~cm}$ to $0.32 \mathrm{~cm}$. The ground plane initiates and guides the plasma channel and has a strong effect on its size. A smaller ground plane initially forms a smaller diameter discharge with higher impedance. The results are shown in fig. 6 . 


\section{BANK DESIGN}

We used our parameterization data to modify the PFN. The impedance of the bank was lowered to 1-ohm, while at the same time, the impedance of the lamps was raised to near an ohm, by increasing the number of lamps, and adjusting the pressure upwards. The bank impedance was also tapered to flatten the output pulse. The resulting output pulse has a falling flattop characteristic, but since photographic response is logarithmic, the exposure appears to be constant during the discharge. The PFN is shown in Fig. 7, and consists of the inductors $\mathrm{L} 1$, and $\mathrm{L} 2$, and the capacitors, $\mathrm{C1}$, and $\mathrm{C2}$. The ignitron, S1, initiates the trigger sequence, connecting the Initial Breakdown Capacitor (IBC), which is external to the PFN, to the lamps through the

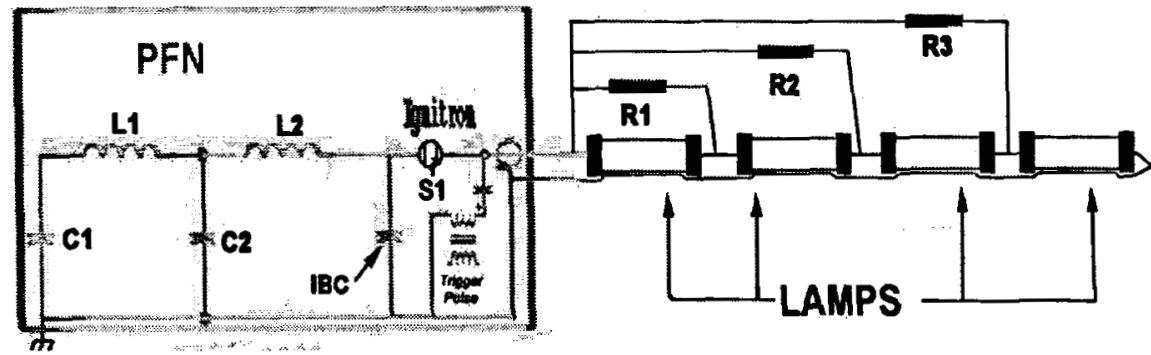
triggering circuit resistors, $\mathrm{R} 1, \mathrm{R} 2$, and $\mathrm{R} 3$. The trigger transformer, TT, breaks down the lamps, while the IBC continues to supply energy until the PFN can sustain the plasma channel in the lamps. The IBC, the trigger transformer, $T T$, and the resistors, $R 1, R 2$, and $R 3$, were added to assist in triggering the lamps.

Fig. 7, Schematic of the PFN and Lamp System

\section{LIGHT OUTPUT}

Simultaneous photographic and photometric measurements were taken of both a PAL (4, series lamps), and a $15 \mathrm{~cm}$ Argon candle. Analysis of fig. 8, photograph, with a rotating-mirror camera set at a $1-\mu$ s inter-frame time, shows that the PAL illuminates five times the area, has better color rendition, and a higher light output, than the explosively-driven Argon candle. A PIN diode with a visual band-pass filter, measuring the illuminance of a KODAK $18 \%$ gray card was used to compare the light intensity of both sources, fig. 9. The illuminance we have achieved to date is around 2 Gigalux. Power dissipation at this light output is -670 kilowatts per $\mathrm{cm}$, with $0.91 \mathrm{~m}$ total arc length. Increasing the energy in the arc rapidly reaches the point of diminishing returns, as the spectral peak starts to shift strongly into the ultra-violet at 800 kilowatts per $\mathrm{cm}$.

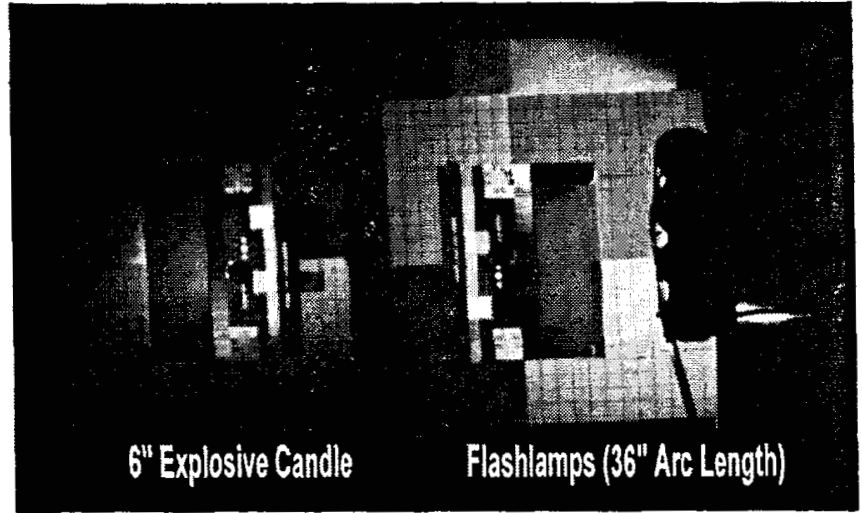

Fig. 8, Photographic Lamp and Candle Comparison Test

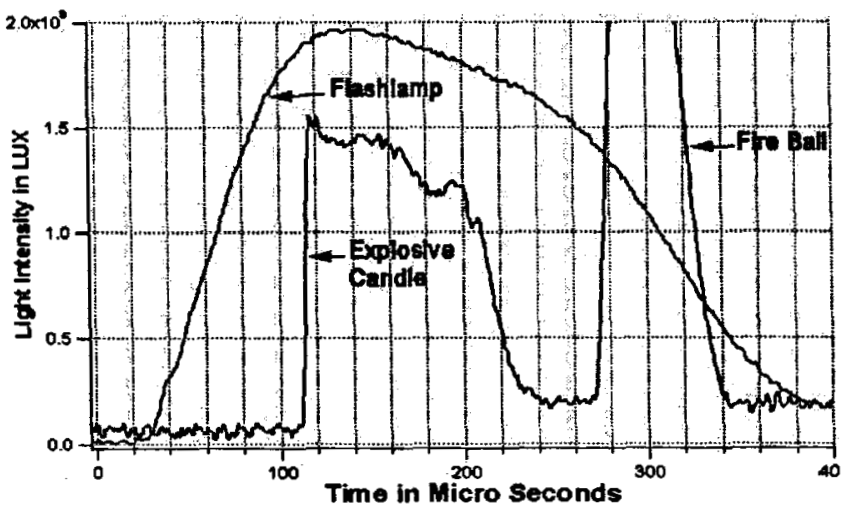

Fig. 9, Photometric comparison of a PAL and an Argon Candle 


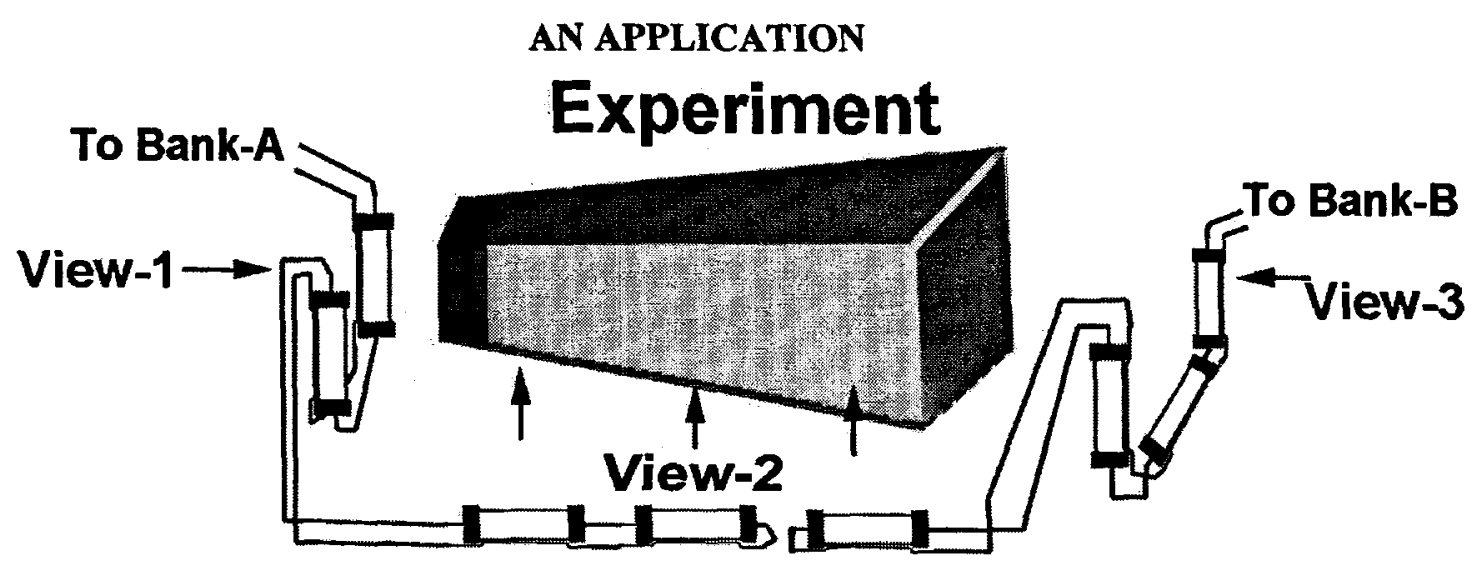

Fig. 10, Experimental set-up, August 2002

The electronic flash lamp system was used on a real experiment in August 2002. The lamps were distributed around the experiment, unlike the configuration in previous illumination tests, in which the lamps were tightly clustered,. In fig. 10, the distribution of lamps and the size of the illuminated area in this experiment is illustrated. Two PFNs drove four lamps each. Two Lamps of Bank-A illuminated the first view, while the remaining two lamps, separated by $76 \mathrm{~cm}$, illuminated two-third's of the second view. Three lamps of Bank-B illuminated the third view, while the fourth lamp, separated by $127 \mathrm{~cm}$, illuminated the remaining third of the second view. The lamps were pressurized with Xenon at 83 $\mathrm{kPa}$, and the banks were charged to $17 \mathrm{kV}$. The flash lamp system replaced $9 \mathrm{Kg}$ of explosives, which would have been required to illuminate the experiment. All three views were evenly exposed with good color saturation. This was the first time Lawrence Livermore National Laboratory applied flash lamps to a full-scale experiment.

\section{CONCLUSIONS}

The change to Plasma Arc Lamps has eliminated diagnostic explosives, and given us the ability to dry run illumination systems. The color temperature of the PAL more closely approximates daylight and illuminates an area 5 times larger than a $15 \mathrm{~cm}$. Argon candle. The lamp cluster can be broken up and the segments individually redistributed around the experiment to illuminate multiple views. PALs have increased the amount of explosives that can be added to an experiment without exceeding the mandated explosive weight limits. This technology also aids in waste minimization programs.

The versatility of Plasma Arc Lamps and their ability to outperform explosively driven candles, verify views, and exposure makes them a valuable tool for high-speed photography. The continued development of the electronic flash lamp system is required in order to meet the future programmatic needs of high speed photography at Lawrence Livermore National Laboratory.

\section{ACKNOWLEDGEMENTS}

This work was performed under the auspices of the U. S. Department of Energy by the University of California, Lawrence Livermore National Laboratory under Contract No. W-7405-Eng-48.

\section{REFERENCES}

1. R.G. Root, and P. Falkos, "Plasma Discharge Replacement for Argon Candles," Proceedings of SPIE, 3642, pp. 116-126, 1999.

2. R.G. Root, D.E. Lambert, D.R. Snyder, and W.L. Stigman, "MegaSun Illumination for Ultra High Speed Photography," Proceedings of SPIE, 4308, pp. 28-37, 2001. 